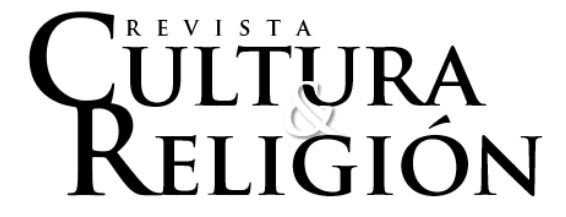

Vol. XIV, Nº 2 (2020) pp. 1-16

Recibido: 31 de julio, 2018

Aceptado: 11 de marzo, 2020

\title{
LA PROPUESTA CULTURAL DE LOS CÍRCULOS CATÓLICOS DE OBREROS EN LA ARGENTINA DURANTE LAS PRIMERAS DÉCADAS DEL SIGLO XX*
}

\author{
The cultural proposal of catholic workers' circles in Argentina during the \\ early 20th century
}

\author{
Yanina Andrea Leonardi ${ }^{* *}$ \\ Universidad de Buenos Aires \\ yaninaleonardi@gmail.com
}

\begin{abstract}
Resumen
Este artículo se propone analizar la propuesta cultural de los Círculos Católicos de Obreros, creados a fines del siglo XIX en la Argentina por el sacerdote redentorista de origen alemán Federico Grote. Si bien su propósito inicial se fundaba en lo político y lo social, los Círculos también incursionaron en el orden cultural, al igual que las formaciones socialistas y anarquistas desarrolladas durante los mismos años. Para ello, se eligió una estructura que retomaba el mutualismo de las asociaciones étnicas y la acción social y cultural de las parroquias. La finalidad de los Círculos era brindar al obrero y a su familia una asistencia que abarcaba desde la salud y la educación hasta el entretenimiento, siempre dentro del marco de los lineamientos morales implementados por el catolicismo. Entre las actividades educativas y recreativas, el arte y el deporte tuvieron roles centrales. Aunque la primera sede de los Círculos estuvo ubicada en Buenos Aires, la presencia de esta formación de índole política y cultural se multiplicó rápidamente por todo el país.
\end{abstract}

Palabras clave: obreros, catolicismo, cultura, política, asociacionismo

\footnotetext{
${ }^{*}$ El presente artículo se inscribe en una investigación mayor que la autora lleva a cabo como investigadora de carrera del CONICET (Consejo Nacional de Investigaciones Científicas y Técnicas de Argentina), titulada "Prácticas y formaciones artísticas de intervención política destinadas a los obreros en la Argentina del siglo XX". La investigación comprende distintas etapas: la primera de ellas abarca las experiencias concretadas por los anarquistas, los Círculos Católicos de Obreros y los socialistas, en un período que se extiende entre fines del siglo XIX y los inicios de la década de 1940.

${ }^{* *}$ Investigadora de carrera del CONICET (adjunta) y doctora en Historia y Teoría de las Artes, Universidad de Buenos Aires (UBA). Profesora de Enseñanza Media y Superior en Letras, UBA, e investigadora del Instituto de Historia del Arte Argentino y Latinoamericano de la Facultad de Filosofía y Letras, UBA. https://orcid.org/0000-0001-5912-6116
} 


\begin{abstract}
This article analyzes the cultural proposal of the Catholic Workers' Circles, which were created in the late 19th century in Argentina by Redemptorist German priest Federico Grote. Although their initial purpose was based on the political and social spheres, the Circles also addressed matters related to cultural life, as did the socialist and anarchist groups formed during those same years. To that end, they chose a structure that returned to the mutualism of the ethnic and social and cultural action associations of parish churches. The purpose of the Circles was to provide the worker and his family with assistance that ranged from healthcare and education to entertainment, always within the moral guidelines provided by Catholicism. Art and sports played key roles in educational and recreational activities. The first headquarters of the Circles were located in Buenos Aires, but the presence of this political and cultural organization rapidly spread throughout the country.
\end{abstract}

Keywords: workers, catholicism, culture, politics, associative cultural practice.

\title{
Introducción
}

En los últimos años del siglo XIX surgió en la Argentina una entidad de índole político-cultural fundada por la Iglesia católica como respuesta a la encíclica Rerum Novarum, con el fin de incidir en la "cuestión social" (Suriano, 2000), constituyéndose a la vez en una medida que pretendía contrarrestar el avance de las agrupaciones políticas de izquierda en la conformación del movimiento obrero. Se trató de los Círculos de Obreros o Círculos Católicos de Obreros (CCO), creados por el sacerdote redentorista de origen alemán Federico Grote, cuya presencia se multiplicó rápidamente por todo el país. Si bien su propósito inicial se fundaba en lo político, los Círculos también incursionaron en el orden cultural, al igual que las formaciones socialistas y anarquistas desarrolladas durante los mismos años. Para ello, el padre Grote eligió una estructura que retomaba el mutualismo de las asociaciones étnicas y la acción social y cultural de las parroquias barriales. El fin de los CCO era brindar al obrero y a su familia una asistencia que abarcaba desde la salud y la educación hasta el entretenimiento, siempre dentro del marco de los lineamientos morales implementados por el catolicismo.

En este sentido, y considerando la existencia de una propuesta cultural, nos interesa indagar en esta, particularmente en las experiencias artísticas planificadas por los CCO con asiduidad a la hora de pensar en la recreación y la sociabilidad de los obreros y sus familias. Asimismo, consideramos que estas experiencias gestadas desde la Iglesia católica nos llevan a repensar el vínculo entre el arte y la política, más allá de un imaginario de izquierda como generalmente se lo restringe. En efecto, desde una institución tradicionalista como la Iglesia católica también se pensó que el arte podía ser una herramienta útil tanto para diseñar la sociabilidad de los obreros como para intervenir en su formación ideológica.

En suma, es nuestro propósito analizar esta formación político-cultural de índole religiosa, destinada exclusivamente al cuerpo obrero, haciendo hincapié en la función cumplida por el arte en el marco del proyecto cultural de los CCO. Nos interesa en particular conocer cuáles fueron las propuestas culturales y artísticas ofrecidas con el fin de indagar en los lineamientos educativos y de esparcimiento ideados por la Iglesia católica. 
Esto también nos permitirá pensar en su concepción del ocio aplicada en el mundo del trabajo. Asimismo, en un plano de reflexión más amplio, podremos considerar la incidencia de estas prácticas y formaciones artísticas en las pautas de sociabilidad vigentes en los sectores obreros de la época, y en las creencias, conductas e imaginarios presentes en la conformación de una identidad y cultura obreras en la Argentina de principios del siglo $\mathrm{XX}$.

Con el fin de cumplir nuestro objetivo, reconstruiremos la propuesta cultural de esta formación a partir del relevamiento de las fuentes presentes en el archivo de la Federación de Círculos Católicos de Obreros, cuya sede está ubicada en la ciudad de Buenos Aires. Allí pudimos acceder a documentos, publicaciones, fotografías e investigaciones sobre los CCO. Asimismo, consultamos otras fuentes como el diario El Pueblo, órgano de la entidad en cuestión. Coincidimos con la observación que realizan otras investigaciones sobre los $\mathrm{CCO}$ en las dificultades para reconstruir la labor de esta formación debido a la poca cantidad de fuentes conservadas.

A modo organizativo, en principio nos referiremos al contexto social y político que atravesaba la Argentina a principios del siglo XX para comprender el marco en el que surgen los CCO. Luego nos ocupamos de la estructura de los Círculos y su proyecto cultural, donde se incluyen diversas actividades y prácticas artísticas, tomando como ejemplo algunas experiencias acontecidas en la provincia de Buenos Aires.

\section{La irrupción de la "cuestión social” en la Argentina}

La Argentina experimentó, en las últimas décadas del siglo XIX, un proceso de modernización que cambió rotundamente la fisonomía que había caracterizado al territorio desde la etapa colonial. Esta Argentina moderna que dejaba atrás los procesos de guerras civiles, los problemas de frontera con los indios y los enfrentamientos con países limítrofes, entraba en una etapa de apertura signada por la dominancia de las políticas liberales, contexto en el que cobraron protagonismo nuevos conflictos internos a la vez que nuevos actores sociales.

En efecto, en el marco de un proceso de expansión económica y social del país, una de las medidas ejecutadas por el Estado fue la incorporación de fuerzas de trabajo de origen europeo, a través de la implementación de la Ley de Inmigración y Colonización (1876). Entonces, la consolidación de un mercado de trabajo local estuvo dada mayoritariamente por la inclusión de inmigrantes provenientes en su mayoría de los países europeos meridionales, cuya incorporación masiva ocasionó un fuerte impacto poblacional y cultural en los centros urbanos y en menor grado en las zonas rurales. Algunos datos a considerar con el fin de comprender el gran impacto producido por las políticas migratorias en el ámbito urbano son los siguientes: la ciudad de Buenos Aires experimentó un crecimiento espectacular, pasando de menos de 200.000 habitantes en 1869 a más de 300.000 en 1878 , más de medio millón en 1890, y un millón en 1905. En los tres censos de Buenos Aires realizados en los años 1887, 1895 y 1904-, los extranjeros representaron siempre más de la mitad de la población. En cifras totales, los emigrantes pasaron de 228.651 en 1887 a 427.850 en 1904, incrementándose la población urbana en ese mismo período de 433.375 habitantes a 850.891 (Zaragoza Ruvira, 1996).

Esta Argentina moderna, que nucleaba a fuerzas de trabajo inmigrantes en tiempos 
aceleradamente vertiginosos, ofrecía condiciones laborales sumamente precarias que tuvieron como pronta respuesta el surgimiento de las protestas y de organizaciones obreras, donde cobró relevancia el accionar de agrupaciones de izquierda, entre las que obtuvieron protagonismo las socialistas y anarquistas. Por ejemplo, ya en 1878, se produjo en la ciudad de Buenos Aires la primera huelga, llevada a cabo por la Unión Tipográfica. Este conflicto, en cierto modo, anunciaba un proceso de luchas obreras que se tornaría constante en las décadas posteriores. De este modo, tal como señala Héctor Recalde (1985), irrumpía "la cuestión social" en el escenario argentino.

Esta organización y conformación del movimiento obrero argentino rápidamente obtuvo como respuesta por parte del Estado medidas represivas que pretendían debilitar su accionar, tales como la declaración del estado de sitio o la sanción de la Ley de Residencia (1902), y más tarde, en 1910, la Ley de Defensa Social.

Desde las últimas décadas del siglo XIX, la Iglesia católica comenzó a prestar atención sostenidamente a los distintos conflictos sociales dados en el marco del mundo del trabajo. Las numerosas huelgas obreras, las protestas por la obtención de los derechos laborales, los conflictos entre trabajadores y patronales, a la vez que la conformación de sindicatos con la intervención de las agrupaciones anarquistas y socialistas fueron las temáticas que estuvieron presentes tanto en la prensa católica como en sus reuniones académicas.

Coincidentemente, en el plano internacional, debemos considerar la difusión e incidencia de las políticas del Vaticano a partir de la encíclica Rerum Novarum promulgada por el papa León XIII, en mayo de 1891. A partir de la misma, la Iglesia católica abordó la cuestión social laboral en un contexto de intensas y numerosas luchas obreras con la presencia de las fuerzas de izquierda. Es así como en su discurso promovió una legislación laboral que apuntaba a resolver los problemas más recurrentes surgidos de los reclamos obreros de la época. Entre ellos, por ejemplo, el descanso dominical, la prohibición del trabajo infantil, los derechos de la mujer trabajadora, la previsión social, el derecho a la asociación laboral, entre otros.

Las repercusiones de la encíclica estuvieron presentes tanto en el accionar del Estado como de la Iglesia católica y el sector empresarial. La creación de los CCO fue una respuesta concreta a la demanda de León XIII en atención a las problemáticas sociales y laborales del momento. Tal como señala Néstor Auza (1987) en su estudio sobre los CCO, la inauguración del primer Círculo "se llevó a cabo el 2 de febrero de 1892, es decir, casi ocho meses después de publicada la Rerum Novarum" (1987, p. 36).

Ante el panorama de las protestas obreras y frente a las repercusiones de la encíclica, la Iglesia católica y el Estado coincidieron en las preocupaciones sobre el tema a principios del siglo XX. Coincidencias que se daban en el marco de las tensiones acontecidas entre ellos a partir de 1880, cuando se produjo -en términos de Roberto Di Stefano- "la embestida laicista", que ni siquiera ocupó toda la década, sino que conoció dos momentos álgidos:

1882-1884, con la discusión y promulgación de las leyes de educación y registro civil, y 1888 , cuando se debate y establece el matrimonio civil. A partir de entonces el empuje laicista se debilita y los sectores anticlericales más duros empiezan a hablar de una 'ola negra' y de una 'invasión clerical' que el poder político tolera y tal vez alienta. (Di Stefano, 2011, pp. 13-14) 
Los CCO tuvieron dos directores espirituales de trascendencia para su desarrollo: su fundador, el sacerdote alemán Federico Grote, quien se desempeñó desde su fundación hasta 1912, y Monseñor Miguel de Andrea, en el período 1912-1915. En esta última gestión, se intensificó el carácter patriótico de las actividades de esta formación. De Andrea, quien había sido formado en las ideas sociales del catolicismo europeo y que contaba con el agrado de las familias de la alta sociedad porteña, consideraba que "sólo la acción organizada de los católicos podría revertir la evolución de las clases obreras hacia el socialismo" (Caimari, 2010, p. 44).

Aunque los CCO aún existen en la actualidad (con un carácter netamente mutualista), su rol, tal como fue concebido por su fundador, tuvo vigencia hasta aproximadamente la década de 1930, siendo su etapa de plenitud los inicios del siglo XX. En los años cuarenta, la actividad de estas formaciones comenzó a declinar notablemente. Sin embargo, se registró la fundación de algunas sedes de los CCO en algunas localidades del país, en particular, de la provincia de Buenos Aires.

\section{Estructura de los CCO}

Los CCO seguían el modelo de las formaciones homónimas creadas en Francia por el conde de Mun, en la década de 1870. Según Grote, eran formaciones abiertas que no requerían la pertinencia obligatoria a la religión católica, de ahí que su denominación "Círculos Obreros" no se restringía a una comunidad en particular, sino que, por el contrario, pretendía tener una llegada más amplia con el fin de difundir el credo. Recién en la década de 1930 estas agrupaciones incorporaron el término "católicos" a su nombre. De todos modos, más allá de sus denominaciones, los Círculos sí profesaban entre sus socios una moral y conducta que respondiesen a la tradición cristiana católica a través de la implementación de conferencias, cursos, lecturas y otras actividades que integraban su quehacer cultural.

Según su Estatuto, la finalidad de los Círculos era:

Defender y promover el bienestar material y espiritual de la clase obrera en marcada oposición a la funesta propaganda del socialismo y de la impiedad, que mediante promesas engañosas de efímera felicidad, llevan al obrero a su ruina temporal y eterna y acarrean a toda la sociedad males incalculables. (Auza, 1987, p. 33)

Es decir, su propósito central era eminentemente político, y residía en combatir la organización de la clase obrera según los lineamientos de una ideología de izquierda. Para ello, los Círculos entablaron un vínculo con asociaciones patronales disconformes con los reclamos sindicales y aun más con las leyes laborales implementadas por el Estado. Ante las huelgas - muy numerosas en las primeras décadas del siglo XX-, los CCO proporcionaban fuerzas de trabajo que le permitiesen a la patronal continuar con la producción. Al respecto, uno de los diarios perteneciente al ámbito católico y órgano de los CCO afirmaba: "A pedido de los patrones reunidos, el Círculo de Obreros envió esta mañana 350 obreros, aumentándose durante el día a 500. Un escuadrón de seguridad protegía a esos trabajadores" (El Pueblo, 10 de diciembre de 1901, p. 5). En efecto, según sostiene María Ester Rapalo (2012), "su objetivo era fomentar la existencia de núcleos madre integrados por trabajadores leales a sus empleadores" (2012, p. 28). 
Pero su plan de concientización ideológica destinado a los obreros también incluía un proyecto cultural que buscaba disputarle el terreno no solo a las agrupaciones de izquierda (anarquistas, socialistas), sino también a la cultura popular urbana, que era considerada como un factor que ponía en riesgo la moral de los obreros. Con ese fin, los CCO se erigían como un lugar de sociabilidad con una impronta mutualista, educativa, recreativa y moralizante. El obrero encontraba allí un espacio que habilitaba la interacción con los pares, a la vez que se le ofrecían asistencia social, educación y recreación por medio del arte y el deporte.

La composición de los Círculos fue inicialmente masculina y diferenciada, alejándose de toda aproximación a una distinción de clase, ya que en ellos convergían tanto trabajadores como representantes de la patronal en una planificada armonía. En su formación se reunían distintos tipos de socios, organizados con ciertas jerarquías: "honorarios", "protectores" y "activos". Los primeros se caracterizaban por su "cooperación moral"; los segundos, por su "colaboración pecuniaria". Tal como señala Sánchez Gamarra, biógrafo de Federico Grote, para ingresar a los CCO se establecían determinados requisitos:

Para ser "socio activo" era necesario cumplir con las siguientes condiciones: haber cumplido 14 años y no pasar de los 70; ejercer profesión o industria honesta; gozar de buena salud en el momento de ingreso; no estar afiliados a sociedades anticatólicas; observar buena conducta desde el punto de vista moral. (Sánchez Gamarra, 1997, p. 200)

La investigadora Miranda Lida (2015) señala la composición interclasista de los $\mathrm{CCO}$, su carácter reformista y su pronta afinidad con los sectores de poder en las primeras décadas del siglo XX:

El presidente Sáenz Peña, próximo al movimiento católico -un fiel aliado para su programa reformista-, estuvo presente, por ejemplo, en la ceremonia de inauguración de una modesta sede barrial de los círculos de obreros, de la parroquia de San Cristóbal, en Balvanera. El vicepresidente Victorino de La Plaza tuvo por su parte un gesto similar cuando se acercó a la iglesia de Santa Felicitas para inaugurar un comedor popular. El gobierno reformista, impulsor de la ley electoral de voto secreto y obligatorio que sería sancionada en 1912, desde luego veía con buenos ojos acercarse a una institución como la Federación de Círculos Obreros, que combinaba bien su retórica popular, aunque no clasista, con sus modales burgueses. Los círculos habían pulido su perfil a lo largo de casi dos décadas de existencia, y más en la ciudad de Buenos Aires. Habían comenzado por barriadas más o menos populares, pero terminaron asentándose en todas partes, y adquirieron a lo largo del trayecto fuertes dosis de respetabilidad. (Lida, 2015, p. 67)

Uno de los grandes anhelos de los CCO era alcanzar un local propio donde desarrollar sus actividades. Este objetivo no siempre era logrado con facilidad, y para ello se realizaban todo tipo de gestiones ante autoridades estatales, municipales y eclesiásticas, e incluso, pedidos a privados, que muchas veces eran atendidos. En el caso de los CCO que no obtenían local propio, era común su funcionamiento en las parroquias barriales. El alcance de ese espacio físico propio potenciaba la identidad del Círculo y expandía su alcance en la comunidad. Muchos CCO complejizaban su oferta por medio de la construcción de amplios salones de actos y canchas de diversos deportes. 
En el ámbito de la Capital Federal, se encontraban los Círculos con edificios más complejos. Por ejemplo, el CCO de Balvanera (Cangallo 2576) contaba en su local con salón de billares y cancha de básquetbol. Organizaba torneos entre sus socios, que alcanzaron a ser 552. El CCO de Belgrano (Echeverría 1360), que tenía 449 socios, poseía un salón de fiestas, y un espacio que funcionaba como Universidad Popular. El CCO Betania, ubicado en Medrano 752, contaba con 153 socios. Su edificio ofrecía una Universidad Popular (donde asistían 140 alumnos), una biblioteca, salón de billar y pingpong, cancha de básquetbol y un salón de actos (Federación de los Círculos Católicos de Obreros, 1943).

Si bien los CCO dependían de una institución de centralidad como la Iglesia católica, su estructura puede ser entendida como una "formación", en términos de Raymond Williams (1994), ya que retoma en gran parte formas de organización cultural ya presentes en la sociedad de la época, tales como las asociaciones étnicas, de fomento y mutualistas, creadas por los sectores populares para canalizar sus intereses de diversa índole. Asimismo, en lo que respecta a las actividades artísticas e intelectuales, se pueden establecer comparaciones con las formaciones de izquierda de aquellos años, como por ejemplo, los "círculos anarquistas".

El modelo inicial estuvo dado por el Círculo Central, situado en la Capital Federal. El Estatuto promulgado por los CCO comprendía una serie de núcleos que se pretendían estructurales de la formación. Estos eran: la aplicación del socorro mutuo en casos de enfermedad; fundación de escuelas primaria para niños (hijos de socios) y clases nocturnas para adultos; creación de agencias de trabajo; actividades de recreación honesta, en particular, actos festivos en los locales propios; conferencias sobre temas morales y religiosos; formación de bandas musicales; creación de cajas de ahorro; celebración de congresos obreros, entre otros (Auza, 1987; Sánchez Gamarra, 1997).

Sin embargo, en la práctica no todos los Círculos podían abarcar los núcleos que el Estatuto requería, debido a las dimensiones de su estructura. En términos generales, y según el relevamiento de fuentes realizado, observamos que el proyecto cultural de los CCO para incidir en el mundo del trabajo concretamente se vehiculizaba a partir de distintos instrumentos que le permitían intervenir en la vida cotidiana y cultural de los obreros, estableciendo marcos de sociabilidad, costumbres y usos del tiempo libre, a la vez que se ofrecía un marco de contención social.

A continuación, nos detendremos en algunos de esos ejes, quizás los más recurrentes, que estructuraban el funcionamiento de los $\mathrm{CCO}$ en las distintas formaciones desarrolladas en el territorio argentino.

\section{Mutualismo}

El mutualismo constituía uno de los ejes centrales de la estructuración de los CCO, por medio del cual se brindaba protección social a los obreros, muchos de ellos de origen inmigrante. Los Círculos se caracterizaron por ofrecer asistencia médica y social a sus socios, incluyendo ayuda económica en casos de gravedad. La asistencia ante la muerte, que cubría los gastos del sepelio, era una de las coberturas que brindada. La construcción de panteones propios fue uno de los logros en la Capital Federal, cuestión que las formaciones de otras localidades provinciales trataron de alcanzar, lográndolo en algunos 
casos. En este aspecto, se observan similitudes con la labor llevada a cabo por las asociaciones étnicas.

Este carácter mutualista habilitó una convocatoria más amplia dentro del mundo del trabajo, tal como lo describe la investigadora Jessica Blanco:

La categoría de socio mutualista se creó como respuesta al pedido de algunos dirigentes sindicales de que los afiliados a sus sindicatos pudieran asociarse solamente a la mutualidad del Círculo para contar con esos beneficios. Esto no significaba convertirse en socio de la institución, pero el CCOC no desaprovechó este vínculo aunque muchos de estos trabajadores no cumplían con los "requisitos morales" para integrarse a la asociación. Cabe aclarar que este socio mutualista no pagaba una cuota mensual a título personal, puesto que el nexo entre el trabajador y la asociación católica era a través de la corporación, es decir el sindicato, encargado de la erogación ante el Círculo para que sus afiliados tuvieran cobertura mutual. (Blanco, 2013, pp. 6-7)

\section{Educación}

La educación fue el otro eje que respondía a la misma motivación social que el mutualismo. Los Círculos se ocuparon de la formación escolar de sus socios y, en particular, de sus niños. Para ello se concibieron escuelas dentro de las sedes, donde se educaban a los hijos de los socios de bajos recursos gracias al patrocinio de los "socios protectores". En el caso de no poder consolidar una escuela propia, tarea que demandaba un esfuerzo considerable que no siempre era posible mantener económicamente, era común otorgar becas. También se ocuparon de la educación de los adultos. Debemos tener en cuenta que muchos eran inmigrantes y no hablaban el castellano. Por ejemplo, en algunos CCO de la provincia de Buenos Aires, resultaba mayoritaria la cantidad de socios extranjeros. Asimismo, la labor educativa de los CCO para adultos comprendía la capacitación laboral y la enseñanza de oficios. Esta área recibía el nombre de Universidad Popular (UP) -al igual que en las formaciones socialistas- y solamente estaba presente en algunas sedes.

Resultan evidentes las distintas instancias implementadas por el catolicismo para la formación de los obreros cristianos, ya sea tanto desde las UP de los Círculos, como desde la enseñanza técnica de la congregación salesiana (Carrizo, 2009) o desde entidades como la Juventud Obrera Católica (Blanco, 2008).

\section{Biblioteca}

Las bibliotecas constituyeron uno de los espacios de sociabilidad e intervención cultural más recurrentes. Estaban presentes en todos los $\mathrm{CCO}$ y se les daba la misma relevancia que en los círculos anarquistas y socialistas. Es decir, se trataba de insertar al obrero en una cultura letrada, a la que se le sumaba bibliografía referida al catolicismo. Muchas sedes contaban con salas de lectura, que le permitían al obrero tener un espacio adecuado y propio para una tarea instructiva y recreativa. Era común la realización de conferencias que abordaban tanto cuestiones de problemática obrera como de orden religioso.

\section{Prensa}


El proyecto cultural de los CCO se fundaba en la difusión de ideas por medio de la palabra escrita, y con ese fin se organizaron distintos órganos de prensa. El diario El Pueblo -fundado por el padre Grote en 1900- fue el más conocido, y contó con una mayor perdurabilidad. Era editado en el Círculo central, y llegaba a los CCO de otras localidades. De todos modos, muchos Círculos editaron sus propios periódicos, revistas y boletines. Cabe observar que El Pueblo tuvo antecedentes. La investigadora Sabrina Asquini (2013), en sus estudios sobre la labor social de los CCO, señala que La Defensa fue el primer órgano de difusión, si bien tenía una dimensión menor y no abordaba toda la organización de la entidad.

\section{Deporte}

El deporte era uno de los instrumentos de directa incidencia en el diseño del ocio de los obreros. Con el fin de intervenir en la vida cotidiana y promulgar una sana sociabilidad entre los socios, se promocionaban algunas prácticas deportivas, incluyendo, en algunos casos, espacios deportivos propios en los edificios más completos, tal como señalamos anteriormente. Los deportes más promocionados eran la pelota paleta, el básquetbol y las competencias de bochas. Frecuentemente, se realizaban campeonatos entre los socios, al igual que de juegos de salón, como el billar. Cabe señalar que se trataba de prácticas deportivas que se situaban en un mundo masculino.

\section{Actividades en el espacio público}

Una de las prácticas comunitarias de los CCO eran las procesiones religiosas. Estas se daban en el marco de las celebraciones de fechas religiosas o alusivas al trabajador como el $1^{\circ}$ de mayo, y conformaban una actividad netamente masculina. La más notoria y trascendente fue la realizada anualmente en la Basílica de Luján (provincia de Buenos Aires), pero podían celebrarse en otros lugares. Estas procesiones requerían ciertos rituales y organización, y constituían una imagen pública masiva de los CCO ante la sociedad de la época. Asimismo, en este evento consideramos que convergen varios aspectos que esta entidad trabajaba cuidadosamente. Es decir, las procesiones constituían acontecimientos de gran complejidad, en que los Círculos -en tanto cuerpos sociales, políticos y culturalesocupaban la escena urbana, disputaban el espacio público a las agrupaciones de izquierda, a la vez que construían su propia ritualidad que pretendía ser distintiva. Un dato que nos interesa destacar es que las bandas de música de los CCO muchas veces intervenían en estas procesiones.

Observa Miranda Lida (2011) sobre estas prácticas en el espacio público:

Una vez que comenzó a apaciguarse el conflicto obrero que caracterizó los primeros años del gobierno de Yrigoyen, los Círculos Católicos de Obreros comenzaron a su vez a hacerse ver en la Plaza de Mayo, sea en la visita a los sagrarios que hacían todos los años en ocasión de Semana Santa, o bien en la celebración del $1^{\circ}$ de mayo, que el movimiento católico intentó procurarse para sí (...). Las movilizaciones de los Círculos eran exclusivamente masculinas, y solían apelar a valores como la virilidad y la valentía de sus asistentes. Sólo años después, ya iniciada la década de 1930, monseñor Miguel De Andrea comenzó a 
organizar movilizaciones femeninas, que marchaban en paralelo con la de los hombres, pero sin mezclarse. (2011, p. 114)

\section{Celebraciones}

Las celebraciones constituían otras de las actividades de orden comunitario planificadas por los CCO. En función de mantener a los obreros y a sus familias en el marco de una moral y sociabilidad católica, alejados de actividades como el juego y la bebida, o de la influencia de ideologías contestatarias, los CCO desarrollaron una serie de prácticas de orden celebratorio o festivo en las que se promocionaba un clima de armonía. El evento más recurrente eran las "fiestas"1 (Vidal, 2006), que estaban contempladas en el Estatuto a realizarse con asiduidad, y podían tener como motivo una fecha religiosa o patriótica. En estas celebraciones se advertía una estructura que las caracterizaba: una comida o refrigerio, el dictado de una conferencia de temática religiosa a cargo de los intelectuales o líderes espirituales de los CCO, y la presencia de actividades artísticas que amenizaban la velada. Estas eran: el teatro, la música y el cine. En efecto, el arte era utilizado por los CCO como instancia de esparcimiento y sociabilidad. Era muy común que fomentasen la conformación de una banda musical, o las funciones de teatro, con la presencia, en algunos casos, de cuadros filodramáticos propios o elencos compuestos por niños y niñas, quienes representaban un repertorio ecléctico para toda la familia.

Asimismo, otro de los propósitos de los CCO era tener una sala propia que sirviese para ofrecer estas funciones teatrales, entre otras actividades. Muchos lo lograron, convirtiéndose así en el patrimonio edilicio de su localidad. Las salidas campestres, pícnics y excursiones constituían otra de las instancias de sociabilidad y esparcimiento fomentados por los CCO. Podían darse en espacios públicos o fuera de la ciudad, en el marco de fechas patrias o religiosas, pero no de modo excluyente. También podían incluir a la familia de los socios. Hacia fines de la década de 1920, se incorporó otro evento cultural en la actividad de los CCO de la Capital Federal, que fue la "Semana Social". Se trataba de una serie de conferencias temáticas dictadas por intelectuales católicos, integrantes de los Círculos o líderes espirituales. En octubre de 1927 se realizó por primera vez una de estas, siendo el tema elegido "La familia católica". Posteriormente, las conferencias fueron reunidas en un volumen que se difundía entre los socios de forma gratuita.

La revisión de la labor cultural de los CCO nos permite observar que las disciplinas artísticas intervinientes en sus prácticas fueron -en términos generales- el teatro, la música y el cine. Aunque la primera de ellas haya sido la más recurrente, quizás por su carácter asociativo y comunitario. Asimismo, advertimos que prácticamente se consideraron las mismas formaciones artísticas que las fuerzas de izquierda: los cuadros filodrámaticos, los elencos infantiles o las orquestas y bandas de música. Sin embargo, el contenido de las mismas no se concebía como rupturista con respecto al orden dominante, ni pretendía construir una cultura alternativa, tal como ocurría, por ejemplo, con las agrupaciones anarquistas.

El repertorio y los contenidos difundidos por las artes mencionadas podían ser de temática religiosa -como, por ejemplo, las películas de vidas de santos-, o no. Muchas

\footnotetext{
${ }^{1}$ La investigadora Gardenia Vidal señala que: "El término fiesta se utiliza para mencionar diferentes organizaciones recreativas y religiosas. Reuniones familiares, celebraciones, peregrinaciones, etc. no son conceptos ausentes, pero el término genérico que las agrupaba a todas era el de fiestas” (2006, pp. 25-57).
} 
veces nos encontramos con producciones concebidas por fuera de lo religioso, pero que respondían a la moral cristiana católica. Tal es el caso, en relación con la actividad teatral, de las obras del dramaturgo español Alejandro Casona. El cine fue utilizado intensamente por estas formaciones como instancia de esparcimiento, no solamente destinada a los obreros, sino también a sus familias. Eran comunes las funciones para los hijos de los socios acompañadas de una merienda. Además, cabe observar que los ámbitos de realización de estas prácticas serían dos: uno interno, las celebraciones o "fiestas" dadas en las sedes de los CCO, en general, sus teatros o salones de actos; y uno externo, el espacio público donde se llevaban a cabo las procesiones y excursiones.

En términos generales, podríamos pensar que las prácticas artísticas y culturales de los CCO se concebían como vías para establecer formas de sociabilidad entre los sujetos, como instancias de esparcimiento, o pautas para la recreación durante el tiempo libre, e impartir una instrucción, todo en un marco inscripto ideológicamente en la tradición cristiana católica apostólica romana. De ese modo, se intentaba alejar a los obreros del accionar de las fuerzas de izquierdas presentes en el país, a la vez que de la cultura popular considerada como soez. En este sentido, la función del arte en los CCO puede considerarse como una bisagra que ponía en contacto a la sociedad y la jerarquía eclesiástica, habilitando un vínculo de tipo comunitario que pretendía extenderse e incidir en otros órdenes de la cotidianeidad.

\section{La experiencia bonaerense}

El listado proporcionado por la Federación de los CCO nos permite conocer el considerable desarrollo de esta formación en la provincia de Buenos Aires, ya desde fines del siglo XIX y los primeros años del XX. En un marco nacional, el territorio bonaerense es el que cuenta con mayor cantidad de Círculos, aun en localidades alejadas de sus grandes centros urbanos. Para comprender este desarrollo nos resulta necesario recuperar datos referidos a la población provincial, a sus formas culturales y de sociabilidad, a la vez que a la presencia de la Iglesia católica en este territorio.

El investigador Leandro Losada (2013) refiere que durante el período comprendido entre 1880 y 1943, la pampa gaucha mutó en pampa gringa, por la acción de una masiva inmigración ultramarina; los fortines y las poblaciones dispersas se diluyeron en un intenso proceso de modernización económica. El tamaño de la población aumentó notoriamente; se hicieron visibles nuevos actores sociales, como las clases medias y los trabajadores asalariados, en la ciudad y la campaña. Asimismo, señala que dichas transformaciones tuvieron en el extenso territorio variantes regionales: "fueron más aceleradas en los partidos circundantes a la ciudad de Buenos Aires (el conurbano) que en el interior provincial" (Losada, 2013, p. 123).

De igual manera, estos cambios definieron nuevos perfiles sociales dentro de su población; por un lado, los sectores terratenientes, por otro, los sectores medios urbanos y rurales, a la vez que los trabajadores asalariados. En el plano cultural debemos considerar, en principio, el proyecto educativo a partir de la Ley 1420 de Educación Común (1884), que significaría una herramienta de progreso a la vez que de distinción social. También, el aporte cultural de la población inmigrante, que se concretaría en asociaciones culturales étnicas, caracterizadas por el asociacionismo y el mutualismo. Estas entidades, en cierto 
modo, marcaron en gran parte las pautas de sociabilidad de los pueblos y ciudades de la provincia. A esto deberíamos sumar los centros y bibliotecas socialistas y los círculos anarquistas, que también tuvieron presencia considerable en algunas zonas.

En el marco de este proceso de desarrollo socioeconómico, que implicó hondas transformaciones sociales y culturales, la Iglesia católica no se mantuvo al margen de la misma; por el contrario, experimentó un gran crecimiento, y un ejemplo de ello lo constituyó su avance en la provincia de Buenos Aires. Al respecto, Miranda Lida señala que: en 1852, se podían contabilizar 33 parroquias en la campaña bonaerense, que en 1871 ya eran 51. En 1881 se contaban a su vez 59 parroquias, que habrán de multiplicarse de ahí en más a un ritmo acelerado, luego de la expansión de la frontera, fruto de la campaña del desierto de 1879. En 1904, había un total de 91 parroquias en la provincia de Buenos Aires, que continuarán multiplicándose. Y menos de dos décadas más tarde, en 1921, la provincia contaba no sólo con 54 parroquias más, sino además con 37 nuevas jurisdicciones eclesiásticas de menor jerarquía. Entre 1880 y 1920, se establecieron 86 nuevas parroquias, amén de otras jurisdicciones eclesiásticas secundarias. No menos significativo fue el crecimiento del clero: si en 1900 la diócesis de La Plata contaba con 152 sacerdotes diocesanos, para 1921 ese número se había ya duplicado, hasta alcanzar un total de 320 clérigos que atendían las crecientes capellanías y parroquias de la diócesis. También el clero regular se multiplicó a ritmo acelerado con el arribo de nuevas órdenes religiosas fruto de la inmigración. Crecían junto con ellos las asociaciones parroquiales de distinta índole (beneficencia, caridad, práctica devocional, prácticas litúrgicas, catecismo, etc.) que se nutrían de la participación activa de una feligresía en constante crecimiento, a su vez, gracias a la inmigración masiva (Lida, 2005).

Quizás podamos vincular el desarrollo de los CCO a esta rápida expansión de la Iglesia católica en el territorio bonaerense, ya que este cuenta con tempranas formaciones desde fines del siglo XIX y los inicios del XX, incluyendo algunas tardías en las décadas de 1940 y 1960, perdurando muchas de ellas hasta la actualidad. Cabe señalar que los destinatarios de los CCO bonaerenses fueron los trabajadores urbanos, no estableciéndose un acercamiento decidido al obrero rural, ${ }^{2}$ aunque podían participar acercándose a los Círculos de su zona.

Al poco tiempo de que el padre Grote inaugurara el Círculo Central de la Capital Federal, la provincia contó con sus primeras formaciones. Por ejemplo, de fines de 1895 datan el CCO de Avellaneda y el de Quilmes; de 1896, el de Luján (fundado el 15/08/1896) y el de Saladillo (19/03/1896). En 1897, se fundaron centros en: Chacabuco (14/03/1897), Dolores (16/12/1897), Lomas de Zamora (17/10/1897) y en la ciudad de La Plata (01/01/1907). En 1898 se fundaron los CCO de Lobos (19/03/1898) y Morón (24/04/1898). En los inicios del siglo XX, en cercanía con los festejos del Centenario de la Revolución de Mayo, surgieron los CCO de Bernal (5/07/1903), Mar del Plata (18/10/1903), Carmen de Patagones (15/05/1904), Chascomús (1908), Piñeyro (7/05/1911) y Temperley (5/04/1914). A una etapa más tardía y de menos vigor de los CCO corresponden las formaciones de: San Isidro (28/07/1929), Pigué (14/05/1930), Lanús (01/05/1939), Quilmes Oeste (04/05/1940), San Fernando (25/07/1940), Rafael Calzada (16/08/1940), Verónica (31/03/1943), Munro

\footnotetext{
2 "En ámbitos rurales, en cambio, se destacó la labor de la Liga Social Argentina, fundada por Emilio Lamarca, que promovió el cooperativismo agrario en clave católica, en especial entre chacareros y arrendatarios" (Lida, 2015, p. 71).
} 
(11/07/1943), Jaúregui (02/02/1946), Turdera (19/12/1949), Villa Ballester (04/09/1965) y Cañuelas (19/07/1968).

La estructura que regía las actividades de los CCO bonaerenses era la descrita anteriormente, del mismo modo que sus pautas de sociabilidad y recreación, estableciéndose variantes de acuerdo con la localidad. Por ejemplo, el CCO de Lobos partido ubicado aproximadamente a cien kilómetros de la Capital Federal-, que data de 1898 y que obtuvo su personería jurídica en 1904, construyó en 1936 un panteón social en el cementerio local que mantiene hasta la actualidad. Potenció así su mutualismo, al que sumó los servicios médicos y de farmacia, sin descuidar su actividad cultural.

Por otra parte, el CCO de Chascomús - ciudad situada en la zona centro oeste de la provincia de Buenos Aires, aproximadamente a $200 \mathrm{~km}$ de la Capital Federal-, que data de 1908, se destacó por su labor cultural en la comunidad, fomentado varias actividades artísticas. El propósito de su fundador fue, según la historiadora local Alicia Lahourcade (1991) "elevar el nivel cultural de los asociados y sus familias" (p. 78) . En consecuencia, se abrió una escuela nocturna y los integrantes del CCO se dedicaron animosamente "a formar un grupo teatral y otro musical" (Lahourcade, 1991, p 78). Es así como pudieron contar con un cuadro filodramático propio. La filial Chascomús estableció un modo particular de estructurar sus reuniones, dándole un clima festivo, que funcionaba como atractivo incluso para un público externo a los CCO. Dice al respecto Lahourcade: "el Círculo de Obreros solucionaba el problema muy salomónicamente, primero, adoctrinaba a sus asociados y difundía la doctrina social católica, y luego, a manera de postre, presentaba una obra de teatro que apasionaba a todos" (1991, p. 78).

Es así que, en 1923, y como iniciativa del cura párroco Brazzola, el CCO decidió levantar su propia sede en el centro de la ciudad, frente a la plaza Independencia (en pleno casco histórico de Chascomús). Esta constaba de dos pisos, una superior con sala de recreo, biblioteca y secretaría, y una planta baja, que tenía un hall y un teatro de 350 localidades. El edificio se inauguró el 24 de abril de 1927 -ya fallecido el párroco Brazzola- con una misa, discursos alusivos al evento, una conferencia religiosa y la proyección de una película, tal como describen los diarios de la época. Las actividades del CCO continuaron, mientras la sala teatral era alquilada para espectáculos teatrales y funciones de cine. En la década de 1960, el teatro pasó a la gestión estatal llamándose Teatro Municipal Brazzola, y permanece hasta la actualidad, siendo el teatro oficial de la ciudad.

El CCO de la ciudad balnearia de Mar del Plata -ubicada en la provincia de Buenos Aires- se fundó en octubre de 1903. Según señala la investigadora Carla Sangrilli (s. f.), funcionó en sus inicios en el centro de la ciudad, y posteriormente le fue cedido en usufructo un terreno (Rivadavia y Mitre) junto al colegio parroquial para que allí fuese construido el salón del Círculo. Logró alcanzar un número elevado de socios desde sus comienzos, un total de 192, de los cuales 48 eran argentinos y 146 extranjeros. Este era uno de los motivos por los que los obreros se vinculaban con el área educativa de los CCO; en efecto, esta filial contaba con una escuela, que se establecía como parte fundamental de su accionar, ya que muchos de esos trabajadores extranjeros podían acceder a estudiar castellano. En este CCO, se contaba con la presencia de familias tradicionales locales (Martínez de Hoz era una de ellas) en calidad de socios honorarios, hecho que muestra la armonía entre sectores patronales y obreros, que también puede observarse en el siguiente acontecimiento: la familia Peralta Ramos (otra de las tradicionales de la zona) donó un terreno destinado a la construcción del panteón social. 
El CCO contaba con un boletín, en tanto órgano de difusión, y tuvo la particularidad de incorporar a mujeres, a las que no se les permitía ejercer el voto. Sus instancias recreativas, además de las fiestas y desfiles en los actos patrios, estuvieron dadas por los pícnics en el sur de la ciudad, las comidas, el cine y la música. Su actividad comenzó a declinar en la década de 1930 hasta desaparecer en los inicios de la de 1950.

\section{Algunas consideraciones finales}

El desarrollo de las formaciones de los CCO se hizo extensivo a prácticamente toda la Argentina, concentrándose principalmente en algunas zonas como la provincia de Buenos Aires, tal como antes fue analizado. El repliegue de las mismas se produjo hacia mediados de la década de 1930, más allá de que muchas de ellas perduran hasta la actualidad con un perfil netamente mutualista abierto a toda la comunidad. Tanto las particularidades del contexto sociopolítico de la época como el surgimiento de nuevas entidades laicas, y el avance en los años cuarenta del Estado en materia social, ocasionaron su debilitamiento.

A la hora de indagar en la cultura obrera, consideramos que resulta necesario recorrer cada una de las experiencias que tuvieron a los sectores trabajadores como destinatarios exclusivos. Los CCO constituyen una de ellas, que en general la investigación académica la ha considerado solamente desde su parte sindical, política y social, sin contemplar que hubo otras estrategias de incidencia en el mundo del trabajo, como la cultural.

Más allá de la intervención en la formación política de los trabajadores, con la participación en manifestaciones públicas en reclamo de sus derechos laborales, nos encontramos con una propuesta cultural -en la que el arte jugaba un rol central- que pretendía incidir en la vida cotidiana y cultural de los mismos, estableciendo marcos de sociabilidad, costumbres y usos del tiempo libre que no se limitaban a los trabajadores, sino también a su familia; en particular, a sus hijos. Además, para ello, los CCO diseñaron actividades muy similares a las llevadas a cabo por las formaciones de izquierda, variando, obviamente, sus fines, agentes y fundamentos.

Entonces, a partir de este uso del arte creemos que es necesario repensar el vínculo entre el arte y la política más allá de las prácticas de izquierda. En efecto, desde una institución como la Iglesia católica, en un contexto de modernización de la sociedad donde la cuestión social y las luchas obreras cobraban protagonismo, se pensó que el arte y también el deporte podían ser herramientas útiles tanto para diseñar la sociabilidad de los obreros como para intervenir en su formación ideológica y moral. De ahí que el fundamento de todas las actividades culturales realizadas en los CCO adscribía a una moral cristiana católica.

La propuesta cultural de los CCO adhería a una concepción de la cultura obrera que se vehiculizaba mayormente a través de contenidos occidentales, pertenecientes a una cultura letrada y moralmente cristiana. Resulta dificultoso evaluar la recepción de las variadas actividades y experiencias forjadas en los CCO. En ese sentido, nos interesa retomar la noción de "uso" planteada por Michel de Certeau (2007), quien postula que los usuarios realizan sobre los contenidos recibidos una serie de manipulaciones u operaciones que les son propias, que responden a sus propias prácticas. De estas acciones se desprende, 
por un lado, la adquisición de una competencia cultural que el sujeto irá modificando a partir de los usos realizados sobre los conocimientos dados, y por otro, la obtención de una "conciencia práctica" -en términos de Williams (1980)- que se genera a partir de lo que se está viviendo, bajo la cual cobran relevancia la elaboración de nuevas pautas de sociabilidad.

A partir del presente trabajo observamos la necesidad de profundizar a futuro en los aspectos culturales de la labor de los CCO en nuestro país, habilitando nuevas líneas de investigación que nos permitan reflexionar sobre su impacto comunitario. Entre esos aspectos concretos, nos interesa destacar tres en esta oportunidad. En principio, la existencia de variantes regionales en la propuesta cultural de los $\mathrm{CCO}$ que considere la variedad de formaciones presentes en todo el territorio. Por otra parte, el rol de las mujeres en estas formaciones; y por último, los vínculos existentes entre los CCO y el primer peronismo, período en el que el catolicismo entabla complejas relaciones con la nueva fuerza política, tal como la bibliografía especializada ha señalado (Barry, 2011; Caimari, 2010; Teodoro, 2012; Vidal y Blanco, 2010).

\section{Referencias bibliográficas}

Asquini, S. E. (2013). Los Círculos de Obreros y la cuestión social en la ciudad de Buenos Aires. Una mirada a través de la polémica católico- socialista de 1895. Itinerantes. Revista de Historia y Religión, 3, 133-152.

Auza, N. (1987). Aciertos y fracasos sociales del catolicismo argentino. Tomo I. Grote y la estrategia social. Buenos Aires: Don Bosco-Docencia-Guadalupe.

Barry, C. (2011). Las monjas peronistas: política y religión en la ayuda social 1946-1955. Revista Cultura y Religión, 5(1), 117-134.

Blanco, J. (2008). Componentes identitarios del imaginario de la Juventud Obrera Católica. Cuadernos de Historia, Serie Economía y Sociedad, 10, 83-118.

Blanco, J. (2013). Los Círculos Católicos de Obreros, un actor soslayado en la historia de la sindicalización argentina". Ponencia presentada en las VIII Jornadas de Historia Eclesiástica y III de Archivos Eclesiásticos, Buenos Aires, Argentina, 14 y 15 de junio.

Caimari, L. (2010). Perón y la Iglesia Católica. Religión, Estado y sociedad en la Argentina (1943-1955). Buenos Aires: Emecé.

Carrizo, G. (2009). Educación, género y mundo del trabajo o cómo "fraguar juventudes laboriosas". Actas de las Segundas Jornadas Nacionales de Historia Social, organizadas por el Centro de Estudios Históricos Prof. C.A. Segreti, La Falda, Córdoba, Argentina, 13-15 de mayo. Recuperado de https://cehsegreti.org.ar/historia-social-

2/mesas\%20ponencias/MESA\%208/Ponencia\%20Gabriel\%20Carrizo.pdf [Consultado el 3 de enero de 2020].

De Certeau, M. (2007). La invención de lo cotidiano I. Artes del hacer. México: Universidad Iberoamericana.

Di Stefano, R. (2011). Por una historia de la secularización y de la laicidad en la Argentina. Revista Quinto Sol, 15(1), 1-30.

El Pueblo (10 de diciembre de 1901). 
Federación de Círculos Católicos de Obreros (1943). Cincuentenario de los círculos Católicos de Obreros de la República Argentina 1892-1942. Buenos Aires: Autor.

Lahourcade, A. (1991). Chascomús desde la Platea. Buenos Aires: Autoedición.

Lida, M. (2005). La prensa católica y sus lectores en Buenos Aires, 1880-1920. Prismas. Revista de Historia Intelectual, 9, 119-131.

Lida, M. (2011). La Playa de Mayo de los católicos (1910-1944). En M. Lobato (ed.), Buenos Aires. Manifestaciones, fiestas y rituales en el siglo XX (pp. 109-125). Buenos Aires: Biblos.

Lida, M. (2012). La rotativa de Dios. Prensa católica y sociedad en Buenos Aires: El Pueblo 1900-1960. Buenos Aires: Biblos.

Lida, M. (2015). Historia del catolicismo en la Argentina entre el siglo XIX y el XX. Buenos Aires: Siglo XXI.

Losada, L. (2013). La sociedad bonaerense: tendencias demográficas, grupos sociales y formas de vida. En J. M. Palacio (dir.), Historia de la Provincia de Buenos Aires. Tomo 4. De la federalización al advenimiento del peronismo, 1880-1943 (pp. 123151). Buenos Aires Argentina: Edhasa/Universidad Pedagógica.

Rapalo, M. E. (2012). Patrones y obreros. La ofensiva de la clase propietaria, 1918-1930. Buenos Aires: Siglo XXI.

Recalde, H. (1985). La Iglesia y la cuestión social (1874-1910). Buenos Aires: CEAL.

Sánchez Gamarra, A. (1997). Vida del padre Grote. El apóstol de los trabajadores. Buenos Aires: Federación de los CCO.

Sangrilli, C. (s. f.). La cuestión social en la Mar del Plata de principios del siglo XX. Una mirada desde el Círculo Católico de Obreros. Programa Buenos Aires de historia política del siglo XX. Recuperado de http://historiapolitica.com/datos/biblioteca/sangrilli.pdf [Consultado el 10 de octubre de 2015].

Suriano, J. (2000). La cuestión social en Argentina 1970-1943. Buenos Aires: Editorial La Colmena.

Teodoro, F. (2012). La revista Criterio y el fenómeno peronista. Un acercamiento al discurso y las ideas políticas de los “católicos liberales" en la Argentina (19551962). Revista Cultura y Religión, 6(1), 76-91.

Vidal, G. (2006). Ciudadanía y asociacionismo. Los Círculos de Obreros en la ciudad de Córdoba, 1897-1912. Revista Escuela de Historia, Facultad de Humanidades, Universidad Nacional de Salta, 1(5), 25-57.

Vidal, G. y Blanco, J. (2010). Catolicismo y política en Córdoba, siglos XIX y XX. Córdoba, Argentina: Ferreyra Editor.

Williams, R. (1980). Marxismo y literatura. Barcelona: Península.

Williams, R. (1994). Sociología de la cultura. Barcelona: Paidós.

Zaragoza Ruvira, G. (1996). Anarquismo argentino (1876-1902). Madrid: Ediciones de la Torre.

\section{Cómo citar este artículo}

Leonardi, Y.A. (2020). La propuesta cultural de los círculos católicos de obreros en Argentina durante las primeras décadas del siglo XX. Revista Cultura \& Religión, 14(2), 1-16. 